\title{
AGENT-BASED FIRE-SPREADING MODEL IN A DENSE URBAN COMMUNITY
}

\author{
M. D. Asiddao ${ }^{1}$, V. P. Bongolan ${ }^{1}$ \\ ${ }^{1}$ Dept. of Computer Science, University of the Philippines - Diliman, P. Velasquez St., Quezon City, 1800 Metro Manila Philippines \\ - (mkasiddao1, vabongolan)@up.edu.ph
}

KEY WORDS: Fire, Urban, Dense, Agent-based, Modeling, Philippines, NetLogo

\begin{abstract}
:
Metro Manila, home to twelve-million residents scattered in densely populated cities, grows its population at a rate of $1.21 \%$ annually. Areas of the metro occupied by residents falling under the poverty line have only been increasing in density per year, and have been prone to fire incidents. One such area, Barangay Addition Hills in Mandaluyong City, has fallen victim to two disastrous fires four years apart: in 2016 and 2020. This study aims to accurately model a portion of Barangay Addition Hills when a fire starts in one of the most densely populated blocks while observing firefighters responding to the incident. The agent-based model adapts features from (Wilensky, 2006)'s Fire model and is virtually simulated with the help of two-dimensional satellite images of the area. The firespreading algorithm incorporates solving the heat diffusion equation to determine ignition time of combustible materials per unit area. Firefighters have been incorporated into the model with the help of the Bureau of Fire Protection (BFP)'s Operational Procedures Manual to determine their expected behavior when responding to a fire alarm. Simulations were run on a per-incident basis to determine the total affected area, estimated affected families, and time for the fire to be put under control under varying densities, traffic conditions, firefighter response times and manpower.
\end{abstract}

\section{INTRODUCTION}

The National Capital Region (NCR) is home to the world's most densely populated cities. With at least 46-thousand inhabitants per square kilometer, Manila, along with Pateros and Mandaluyong City, take the top three spots surpassing Iraqi, Indian, and Bangladeshi cities in density (World Population Review, 2019). Out of the top 50 most densely populated cities in the world, 13 of those are located in the Philippines alone.

The metropolitan cities are also no stranger to fire incidents, as according to the Commission on Audit's (COA) Performance Audit Report in 2018, the region experiences an average of 4500 fire incidents on a yearly basis since 2013 - a monumental rate of 12 incidents per day. From 2011 to 2017, a total of PHP31-billion has been lost in property damage from fire incidents across the country - with NCR contributing PHP17-billion in the total costs

With the increasing growth of Metro Manila's population density also comes the increased risk of fire incidents occurring. As the Bureau of Fire Protection allotted PHP13billion for their Modernization Program from 2011 to 2017, the budget was still insufficient in preventing the PHP31billion in property damage caused by 97 -thousand fire incidents across the country in the same period (Commission on Audit, 2019). One fire incident-prone area is the 162hectare Barangay Addition Hills located in the north of Mandaluyong City, housing over a hundred-thousand residents as of 2015 .

Two major fire incidents in 2016 and 2020 took place in said Barangay, reaching the highest alarm level and causing all available fire stations to respond. These incidents were responsible for an estimated PHP10-million in damages and the displacement of more than one thousand families.
This project aims to provide a model for estimating the spread of fires in the northeast portion of Barangay Addition Hills. The agent-based model allows the interactions of fire and firefighter behavior to allow for complex behaviors to arise from the simulation.

The successful implementation of this project allows for the governing bodies of Barangay Addition Hills and other highdensity neighborhoods in the Philippines, as well as the Bureau of Fire Protection, to take decisive actions in preventing major fire incidents, improving neighborhood living conditions, and increasing firefighter capability.

\section{METHODS}

\subsection{Initialization}

The simulation is able to import a map of the neighborhood, on a one-to-one scaling of patches and square meters of land. With the help of Google Maps' satellite imagery of Northeast Addition Hills, portions of the captured $696 \mathrm{~m}$ by $557 \mathrm{~m}$ area were post-processed and categorized according to the following zones:

- Brown Residential Zones

- Green Safe Zones

- Yellow Main Roads

- Black Minor Roads

- Blue Neighborhood Pathways 


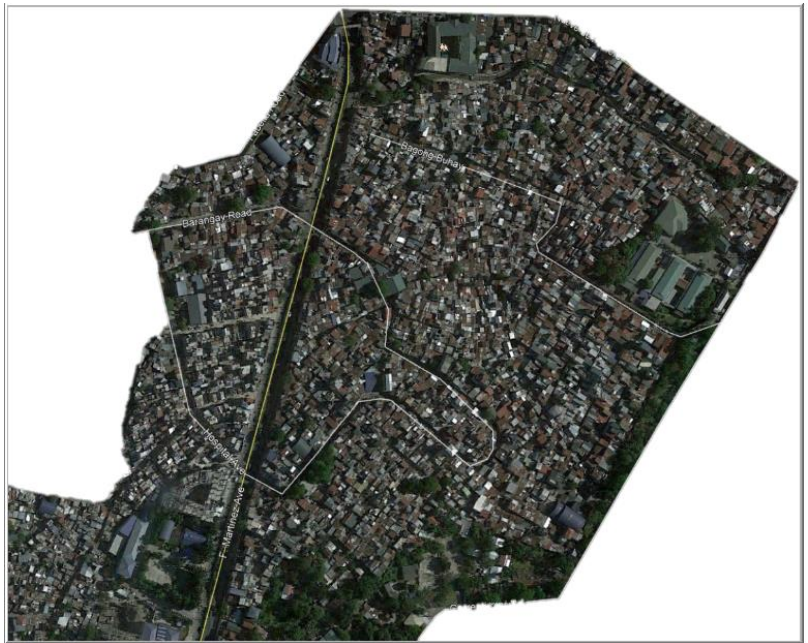

Figure 1. Satellite image of Addition Hills retrieved from Google Earth.

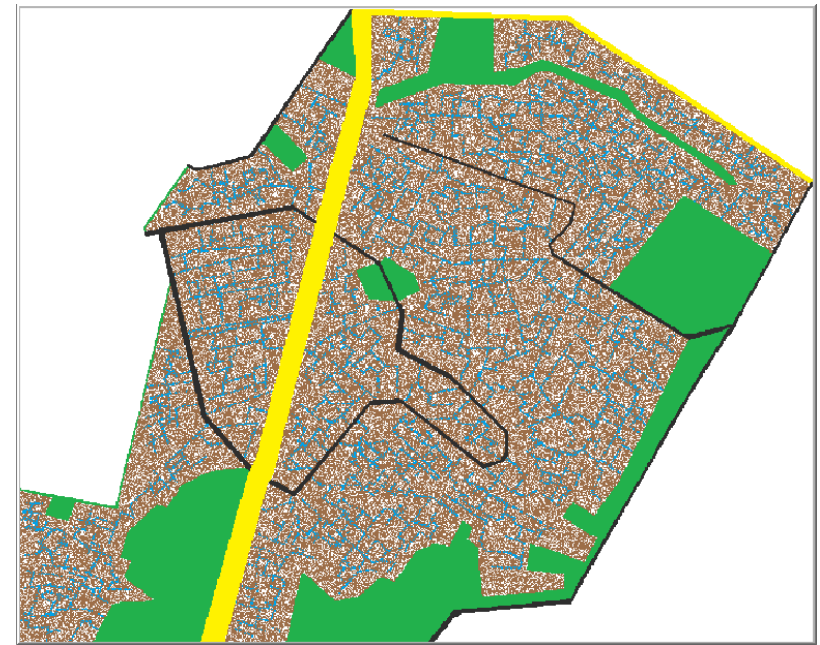

Figure 2. A ready-to-run simulation after post-processing Figure 1 and initialization.

\subsection{Fire Behavior}

Heat transfer is limited only to conduction: the model simulates fire by means of neighboring combustible materials in close proximity, built on top of (Wilensky, 2006)'s Simple Fire model. House fires burn at a maximum possible temperature of $~ 1000$ degrees Fahrenheit, and may be set as a constant upon ignition.

The following partial differential equation for solving the temperature at $(\mathrm{x}, \mathrm{y})$ at a given point in time is given by the two-dimensional heat equation:

$$
u_{t}=c^{2}\left(u_{x x}+u_{y y}\right)
$$

With different kinds of materials present in the houses of the area of study, all combustible areas have been assigned a timeto-ignition variable: a property defined to be the point at which the area has reached its ignition temperature. Increasing the number of neighboring fires rapidly ignite combustible materials.

\subsection{Firefighter Behavior}

Firefighters, fire trucks, and dispatches have been programmed into the simulation using information gathered from Google Maps' Directions feature, and by following the Operational Procedures from the Bureau of Fire Protection.

As per the manual, the target time for first responders to respond to a scene is between five to seven minutes. Firefighters are dispatched in teams of four to six firefighters per fire truck, with increasing fire trucks required at the incident based on increasing alarm levels. The BFP (Bureau of Fire Protection) estimates a required four teams for every increasing alarm level, and the highest alarm level, the General Alarm, will dispatch all available firefighting teams within Metro Manila. The BFP estimates a minimum requirement of 80 teams by the time the General Alarm is called. Task Force Charlie and higher alarm levels did not have quantifiable estimates of infrastructure affected, therefore skipping to General Alarm directly from Task Force Bravo.

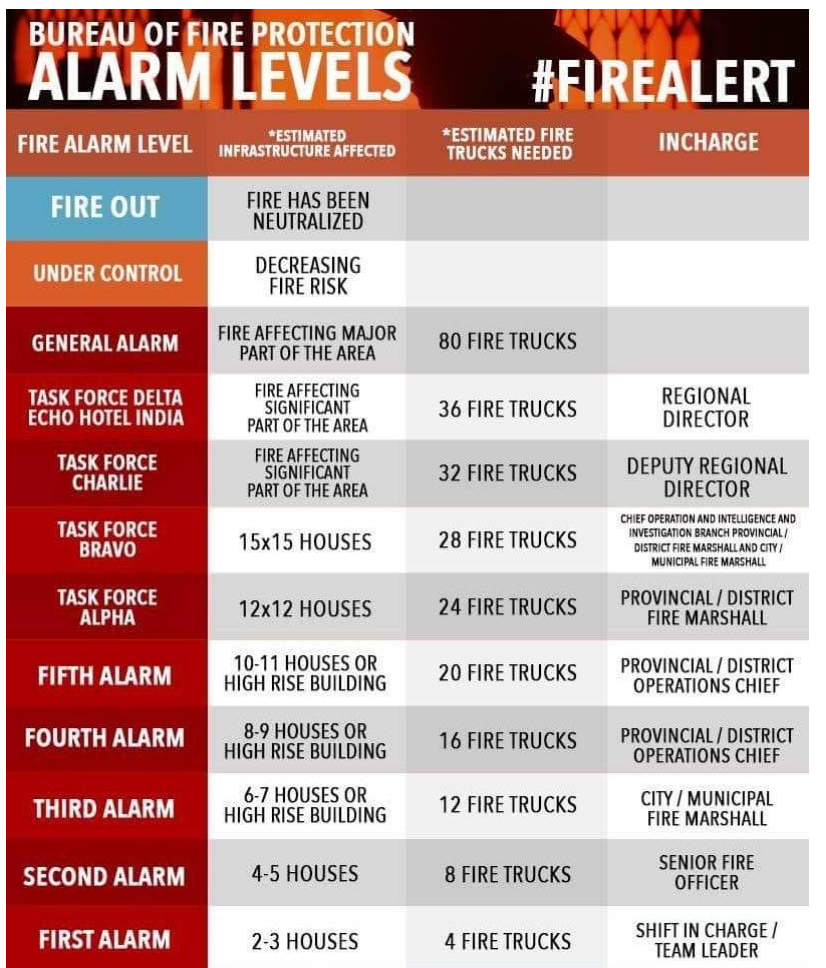

Figure 3. An infographic provided by the BFP indicating estimates of affected buildings and fire trucks.

Firefighting teams will appear at the simulation after the estimated time of arrival is calculated. Information gathered from the firefighting directory and Google Maps' Directions generates an input file consisting of the distance between the fire station and Addition Hills, and the direction they will appear in. Decreasing or increasing the average fire truck speed affects their estimated arrival time.

Fire trucks appear in the simulation on their designated arrival time. These agents will move along main roads, getting as close to the fire as possible before deploying their team. 
Firefighters move faster along pathways and roads and slower while burning structures surround them. Firefighters will always aim to contain the spread of the fire, preventing other houses from being affected, before trying to extinguish the remaining fires. Extinguishing rate of firefighters has never been measured; for the purpose of this experiment, firefighters are estimated to extinguish one square meter of fire in one minute - the equivalent of 100 ticks, set as a variable. Firefighters are programmed to target the nearest spreadable fire, with a maximum of two teams working together per house. Once firefighters have contained the spread, alarm levels will no longer increase. New firefighters will still arrive at the neighborhood, but teams will no longer be queued. The experiment ends when the last fire in the neighborhood has been extinguished.

\section{RESULTS}

As a point of comparison, simulations were run and compared against a baseline setup of

- a community density of 70 percent

- a constant fire truck speed of $35 \mathrm{~km} / \mathrm{h}$

- initial firefighter response time of 500 ticks, corresponding to five minutes in real time

- four firefighting teams per increasing alarm level with five firefighters per team

Simulations have been performed over varying densities between 50 to 80 percent, starting with the area at the center of a major portion of residences in Addition Hills. Fire spread drastically increases between 70 and 80 percent density. At 70 percent density, alarm levels consistently reach up to Task Force Alpha, whereas at 80 percent, a General Alarm is called. At 75 percent density, alarm levels have been reaching Task Force Bravo. Changing the community density directly affects the fire alarm level.

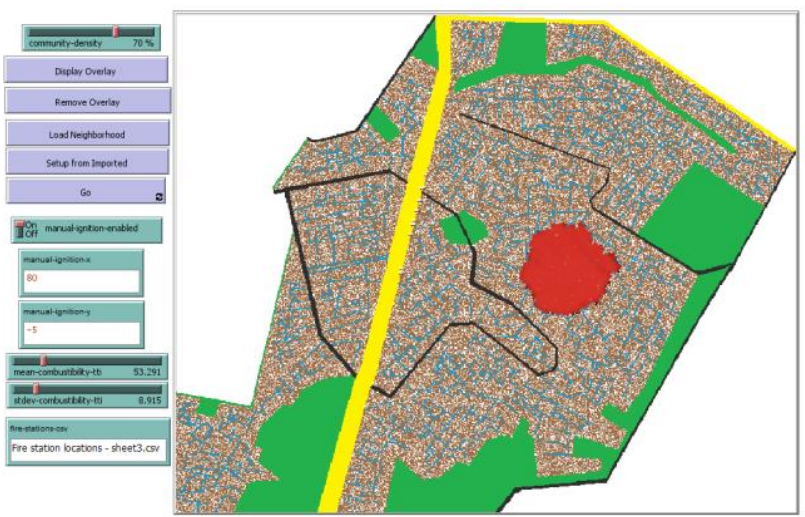

Figure 4. Simulation ran at $70 \%$ density in BFP standard estimates, reaching Task Force Alpha alarm level.

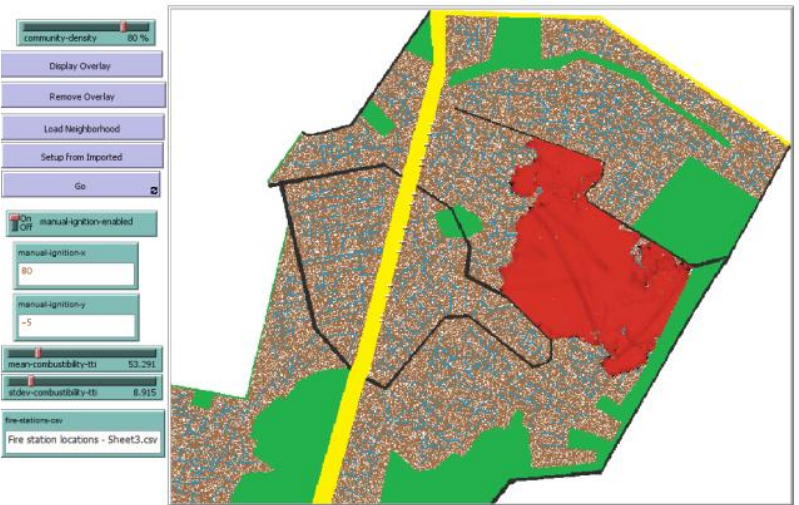

Figure 5. Simulation with the same variables at $80 \%$ density, reaching General Alarm level.

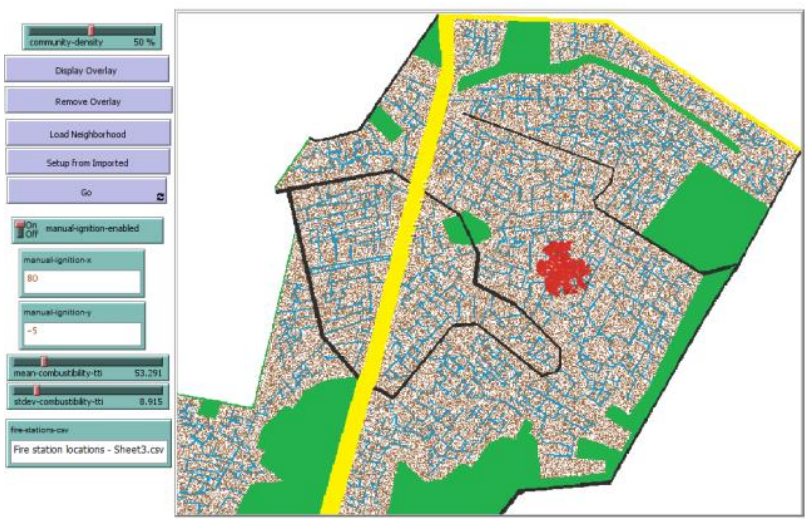

Figure 6. Simulation running at $50 \%$ density using the same variables as Figures 4 and 5 .

Simulations have been run with increased capacity per alarmlevel, and show a drop in fire-out time but not in mitigation of fire-spreading. Average fire control time lowers in community densities past 75 percent: density values that consistently reach the General Alarm. Average Fire Out Time lowers significantly at 5 fire trucks per alarm level, as evident in Figure 8 .

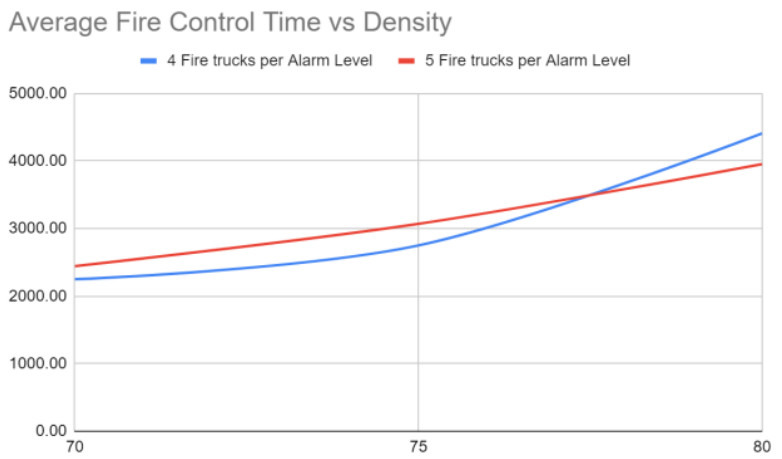

Figure 7. Graph of fire control times at $70-80 \%$ density with increased fire truck responses. 


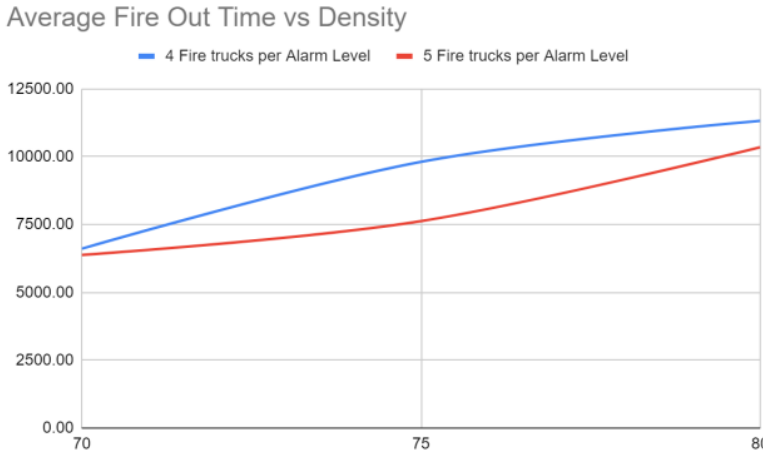

Figure 8. Graph of fire out times at 70-80\% density with increased fire truck responses.

In experiments where the average fire truck speed was made faster by an additional $10 \mathrm{~km} / \mathrm{h}$, hectares and families affected, on average, have dropped by nearly 10 percent. If fire trucks had slowed down by as little as $5 \mathrm{~km} / \mathrm{h}$, the fire spread increased by 15 percent.

\section{Average Hectares Affected vs Average Speed}

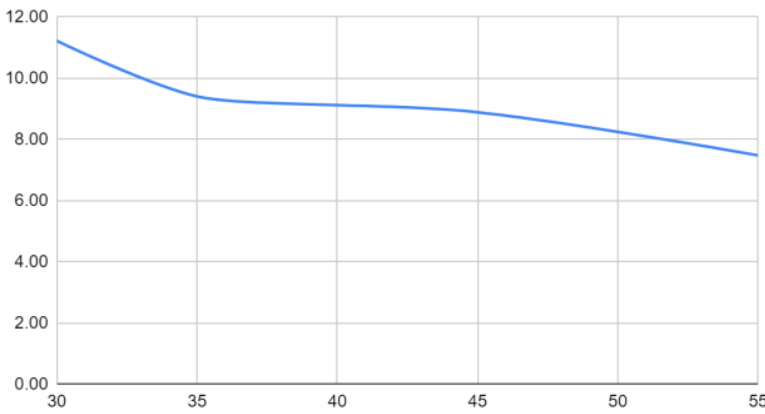

Figure 9. Graph of Average Hectares Affected for simulations done at $70 \%$ density with speeds between 30 and $55 \mathrm{~km} / \mathrm{h}$.

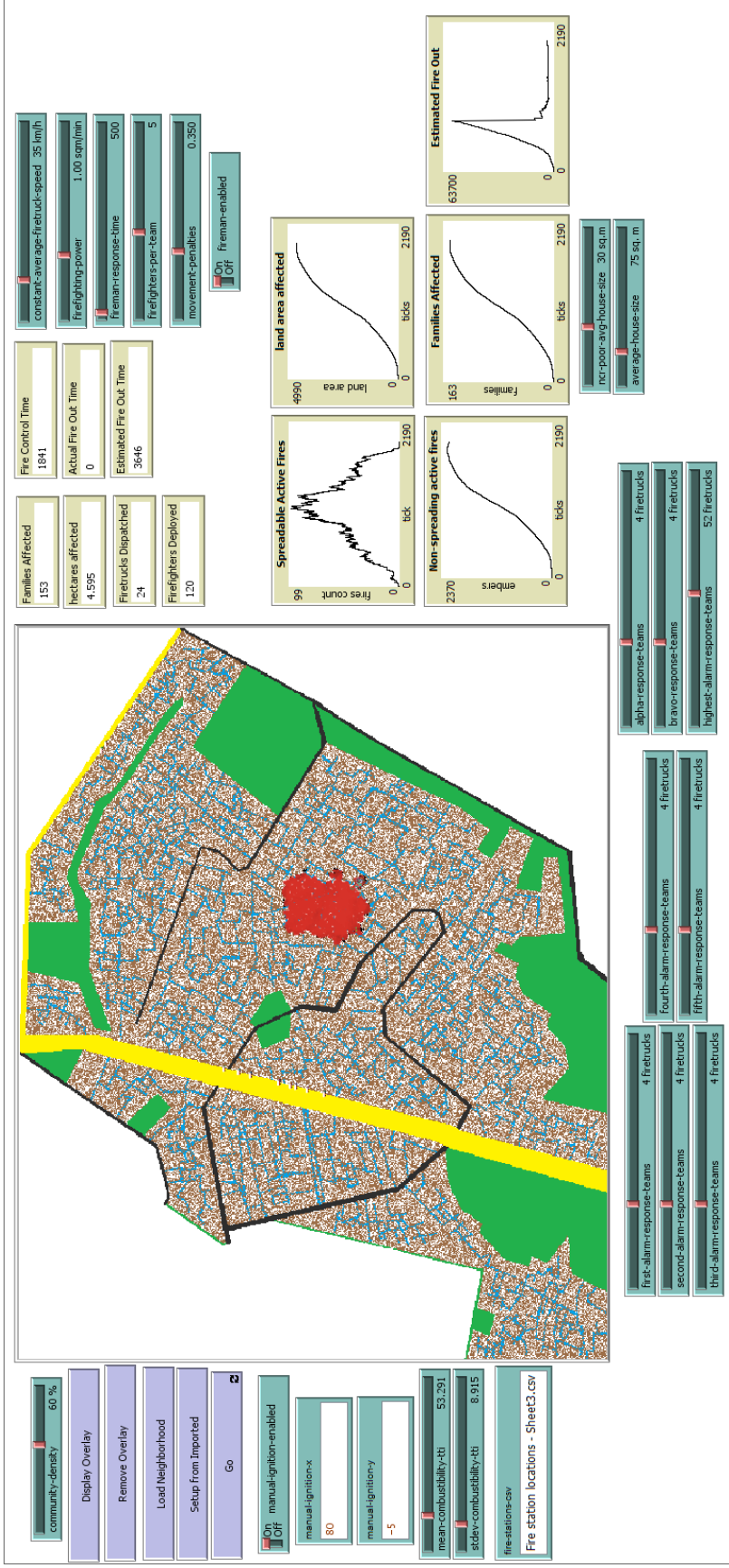

Figure 10. A larger view of the whole experiment at $60 \%$ density, showcasing the graphs and variables used in the entirety of the experiment.

\section{DISCUSSION}

Increasing the community density shows that firefighters will lack the firepower to extinguish the rapidly spreading fires. At 80 percent community density, fires are hard to keep at bay: only with the help of surrounding minor roads are firefighters able to contain the fire from spreading any further. At 60 percent density, firefighters are able to contain the fires at the Task Force Alpha alarm level. At 40 percent density, alarm levels have dropped down to the Third Alarm. Constantly reducing density shows that the current BFP estimates of firefighter manpower have less spreadable fires to extinguish, therefore containing the fires at a much faster rate. 
Increasing firefighter manpower by adding one more firefighting team per alarm level shows only minor improvement in cutting down fire control time. At 70 percent density, the families affected nearly stayed the same, and the time to control the fire, on average, only lowered slightly. Neither was there significant improvement at 75 and 80 percent density, as alarm levels still managed to consistently reach Task Force Bravo and General Alarm, respectively. Increased manpower, however, managed to reduce fire-out times by a significant amount: fires are put out 15 percent faster than usual.

Increasing average fire truck speeds have shown significant effects in preventing fire-spreading. Fire truck speed correlates to traffic conditions in Metro Manila, and the region is notoriously known for slow-moving traffic during rush hours on weekdays. After increasing the average fire truck speed from 35 to $45 \mathrm{~km} / \mathrm{h}$, hectares affected by fires were reduced by as much as nine percent. Further increasing the average speed to $55 \mathrm{~km} / \mathrm{h}$ showed an improvement of up to 23 percent.

Several experiments at 80 percent density show that the fire is naturally mitigated with the help of the minor roads connecting the north and south of the residential area. If these roads did not exist, then, under the same setup, firefighters may never be able to contain the fire. Natural fire mitigators such as wide roads and safe zones prove to be very effective in preventing fire from spreading within the neighborhood.

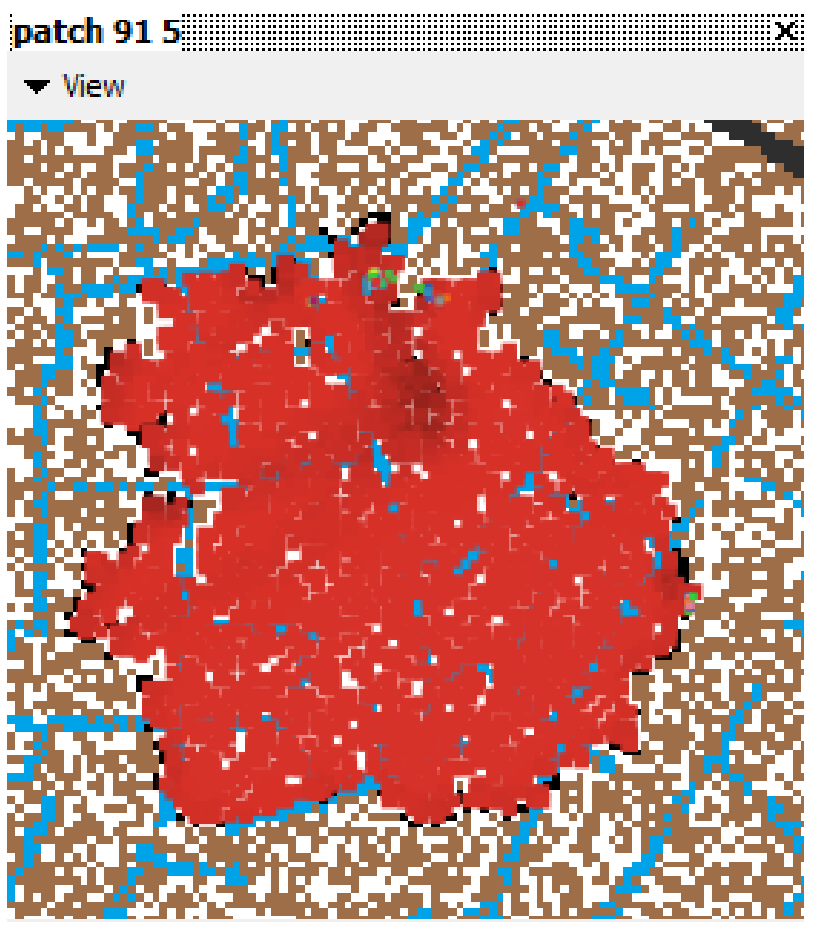

Figure 11. A fire being contained while at $60 \%$ density, bounded by blue walkways in many areas.

Neighborhood walkways contributed as minor barriers in preventing the spread of fires. Notice how in Figure 9, firefighters have contained the fire with blue borders around the perimeter of the fire. This shows the significance of having wider walking spaces among alleys and respecting gaps between neighboring houses as natural mitigators of fire spread.

\section{CONCLUSIONS}

Of all the variables adjusted to mitigate the spread of fire, the most effective form of prevention is by developing the area by adding roads for accessibility and widening walkways to prevent ignition by close-proximity of houses. Wider walkways have been seen to be effective soft barriers in reducing the spread of fire, while bigger and more roads aid in the ability of fire trucks to gain deeper access into the residential areas without having to make firefighters walk very far from the site.

Community density was also a great factor in preventing the spread of fires. By having reduced combustible possessions among the residents, firefighters have less fires on the outermost perimeter to extinguish, therefore making the containment process faster. Lowering the community density by relocating residents in these areas greatly contributes to lowering the risks of fire incidents from getting out of hand.

The decongestion of Metro Manila's roads had also made an impact in improving the fire control time. Addressing the issue of decongestion is also a universal solution as it not only affects Barangay Addition Hills, but also all fire incidents in the megacity, as firefighters will have quicker and more efficient access to the fire.

Careful consideration of the results of these experiments will help in preventing major fire incidents in Barangay Addition Hills. A reallocation of the Bureau of Fire Protection's resources into improving their facilities, vehicles, and manpower, is very well recommended.

\section{ACKNOWLEDGMENTS}

The authors wish to thank first and foremost Mr. Marlon Asiddao, a long-time firefighter of the Marikina FilipinoChinese Fire Brigade, whom M. D. Asiddao has interviewed and received valuable references from with regards to the Bureau of Fire Protection's Operational Procedures. He has been very accommodating to all Facebook inquiries despite being dispatched at times for some fire incidents.

M. D. Asiddao also wishes to acknowledge the immediate and extended family who had been praying consistently for the success of this research, and supporting via Zoom.

\section{REFERENCES}

Agoncillo, J. A. (2016, November 15). 2 dead, P10M lost in 8-hour Mandaluyong fire. Inquirer. https://newsinfo.inquirer.net/844281/2-dead-p10m-lost-in-8hour-mandaluyong-fire

Bureau of Fire Protection (Ed.). (2015, August 4). Operational Procedures Manual. Bureau of Fire Protection. Retrieved 2021, from https://bfp.gov.ph/bfp-operationalprocedures-manual-2/

Commission on Audit (Ed.). (2019, January 22). Performance Audit Report - Bureau of Fire Protection Modernization Program. Commission on Audit. Retrieved 2021, from https://www.coa.gov.ph/index.php/cy2018/category/7288-bureau-of-fire-protectionmodernization-program 
Congressional Policy and Budget Research Department (Ed.). (2020). FF2020-39: Fire Incidents and BFP Performance. Philippines. Retrieved April 24, 2021, from https://cpbrd.congress.gov.ph/2012-06-30-13-06-51/201206-30-13-36-50/1268-ff2020-39-fire-incidents-and-bfpperformance

Google. (n.d.). Addition Hills. Retrieved May 3, 2021, from https://goo.gl/maps/jCtyBuau6Qy1B7fL7

Lalu, G. (2020, June 1). BFP raises general alarm over Mandaluyong fire. Inquirer.

https://newsinfo.inquirer.net/1284617/bfp-raises-generalalarm-over-mandaluyong-fire

Philippine Statistics Authority (Ed.). (2019). 2019 Annual Poverty Indicators Survey. Philippine Statistics Authority. Retrieved February 24, 2021, from

https://psa.gov.ph/content/annual-poverty-indicators-surveyapis

Wilensky, U. (2006). NetLogo Fire Simple model. Center for Connected Learning and Computer-Based Modeling, Northwestern Institute on Complex Systems, Northwestern University, Evanston, Illinois, USA.

http://ccl.northwestern.edu/netlogo/models/FireSimple

World Population Review (Ed.). (2019). Population Density By City. World Population Review. Retrieved July 25, 2021, from https://worldpopulationreview.com/world-cityrankings/population-density-by-city 